Jurnal ELTIKOM, Vol. 1 No.1, Juni 2017, Hal 34-41

ISSN 2598-3245 (Print), ISSN 2598-3288 (Online)

Tersedia Online di http://eltikom.poliban.ac.id

\title{
PENERAPAN ALGORITMA KRIPTOGRAFI TEA DAN BASE64 UNTUK MENGAMANKAN EMAIL
}

\author{
Siswanto ${ }^{1)}$, M. Anif ${ }^{2)}$, dan Windu Gata ${ }^{3)}$ \\ ${ }^{1,2)}$ Universitas Budi Luhur \\ 3) STMIK Nusa Mandiri \\ e-mail: siswantobl@gmail.com ${ }^{1)}$, m.anif91@gmail.com ${ }^{2)}$,windu.gata@gmail.com ${ }^{3)}$
}

\begin{abstract}
This data security application is designed to secure important email data at PT. Dekai Indonesia especially data policy that contains personal data of the customers. Due to the many important data of the customers then the data security be-comes very vulnerable to the theft and manipulation of data from various parties who are not responsible given the data is also often sent using email facilities. With so many important data that is often also confidential, then the data becomes vulnerable to data theft, data manipulation or email eavesdropping. Such problems may be faced by making the applica-tion to prevent irresponsible parties from reading the file contents of the transaction data. Also guarantees the authentici-ty of sensitive and important data is only acceptable and readable by those who are entitled to data. In this paper the al-gorithm used in cryptography, ie TEA cryptography algorithm (Tiny Encryption Algorithm). The use of cryptographic sys-tem is intended to make the data is not easily broken. The programming language used in building data security applica-tions is a web-based PHP programming language. As a result of this cryptographic testing, data can be secured to avoid cryptanalysis attacks. The average encrypt file size has increased by 33.29512 percent of the original file size before going through the encrypt process. The average change in file size that has gone through the decrypt process will be reduced by 25.0231 percent.
\end{abstract}

Keywords: Cryptography Algorithm TEA, Decript, Encrypt, Email Insurance Data Policy, PHP.

\begin{abstract}
ABSTRAK
Aplikasi pengamanan data ini dirancang untuk mengamankan email data penting pada PT. Dekai Indonesia terutama data policy yang berisi data pribadi para nasabah. Karena banyaknya data penting para nasabah maka keamanan data tersebut menjadi sangat rentan terhadap pencurian dan manipulasi data dari berbagai pihak yang tidak bertanggung jawab mengingat sering juga data tersebut dikirimkan menggunakan fasilitas email. Dengan banyaknya data penting yang sering juga bersifat rahasia tersebut, maka data tersebut menjadi rentan dengan pencurian data, manipulasi data atau penyadapan email. Permasalahan tersebut dapat dihadapi demgan membuat aplikasi untuk mencegah pihak yang tidak bertanggung jawab dapat membaca isi file dari data transaksi. Juga menjamin keaslian data sensitif dan penting hanya dapat diterima dan dibaca oleh orang-orang yang berhak mendapatkan data. Dalam penulisan ini algoritma yang digunakan dalam kriptografi, yaitu algoritma kriptografi TEA (Tiny Encryption Algorithm). Penggunaan sistem kripto-grafi ini dimaksudkan agar data tersebut tidak mudah dibobol. Bahasa pemrograman yang digunakan dalam mem-bangun aplikasi pengamanan data ini adalah bahasa pemrograman PHP yang berbasis web. Hasil dari pengujian kriptografi ini, data dapat diamankan untuk menghindari serangan cryptanalysis. Rata-rata ukuran file yang telah me-lalui proses encrypt bertambah sekitar 33,29512 persen dari ukuran asli file sebelum melalui proses encrypt. Rata-rata perubahan ukuran file yang telah melalui proses decrypt akan berkurang sebesar 25.0231 persen.
\end{abstract}

Kata Kunci: Algoritma kriptografi TEA, Decript, Encrypt, Email Data Policy Asuransi, PHP. 


\section{PENDAHULUAN}

$\mathrm{P}$ T. Dekai Indonesia adalah perusahaan yang bergerak di bidang consultant asuransi. Dengan demikian, sebagai consultant banyak data yang bersifat rahasia seperti data policy asuransi, data diri, data keluarga, data riwayat kesehatan, data penghasilan dan juga banyak dokumen lain yang bersifat rahasia, sering juga data tersebut dikirimkan menggunakan fasilitas email. Secara sederhana pengertian email adalah format surat dengan cara digital atau dituliskan melalui media komputer atau bisa juga gadget lainnya yang bisa diproses dengan menggunakan media internet [1].

Dengan banyaknya data penting yang sering juga bersifat rahasia tersebut, maka data tersebut menjadi rentan dengan pencurian data, manipulasi data atau penyadapan email. Saat ini penggunaan keamanan data di PT. Dekai Indonesia masih menggunakan sistem manual yaitu berupa penyimpanan hard copy data dalam berkas, dan juga soft copy tanpa ada pengamanan data pada datanya langsung. PT. Dekai Indonesia belum memiliki fasisitas keamanan berbasis kriptografi dan juga fasilitas pengamanan konten email, sehingga masih rentan terhadap dengan pencurian data, manipulasi data atau penyadapan email.

Demi keamanan data PT. Dekai Indonesia, maka salah satu cara yang harus dilakukan adalah dengan melakukan encrypt pada data yang akan dikirim sehingga hanya pihak yang berhak atas data tersebut yang memiliki kunci untuk membuka data. Salah satu alternatif yang dapat digunakan untuk menjaga kerahasiaan informasi tersebut adalah dengan menyamarkannya menjadi bentuk tersandi yang tidak bermakna. Hal tersebut dapat dilakukan dalam kriptografi [2].

Tiny Encryption Algorithm (TEA) merupakan suatu algoritma sandi yang diciptakan oleh David Wheeler dan Roger Needham dari Computer Laboratory, Cambridge University, England pada bulan November 1994. Algoritma ini merupakan algoritma penyandian block cipher yang dirancang untuk penggunaan memori yang seminimal mungkin dengan kecepatan proses yang maksimal [3].

Algoritma Base64 merupakan salah satu algoritma untuk Encoding dan Decoding suatu daya ke dalam format ASCII yang didasarkan pada bilangan dasar 64 atau bisa dikatakan sebagai suatu metode yang digunakan untuk melakukan encoding (penyandian) terhadap data binary [4]. Umumnya digunakan pada berbagai aplikasi seperti e-mail via MME, data XML, atau untuk keperluan encoding URL

Terdapat penelitian dimana algoritma yang digunakan adalah algoritma Tiny Encryption Algorithm. TEA merupakan algoritma jenis stream cipher yang memproses unit input data. algoritma Tiny Encryption Algorithm (TEA) juga merupakan bagian dari algoritma simetris, dimana proses enkripsi dan dekripsinya memiliki kunci yang sama. Pembuatan aplikasi ini menggunakan bahasa pemograman C\#. Hasil yang akan dicapai dari penilitian ini adalah aplikasi kriptografi dokumen yang bias melakukan enkripsi dan dekripsi dengan algoritma Tiny Encryption Algorithm (TEA) [5].

Pada peneitian lain, algoritma Cryptographic yang akan digunakan adalah Algoritma Enkripsi Tiny (TEA), sedangkan algoritma steganografi yang akan digunakan adalah Least Significant Bit (LSB), data atau informasi yang pertama dienkripsi menjadi TEH, kemudian dimasukkan ke dalam gambar oleh algoritma LSB. Jadi hasil enkripsi dan steganografi tidak akan mencurigakan bagi yang lain, berdasarkan texting, perubahan gambar tidak terlihat. Oleh karena itu dapat disimpulkan dengan menggabungkan Cryptography TEA dan steganografi LSB, sehingga pendalaman data akan lebih akurat dan kinerja program yang baik [6].

Penelitian lainnya membuat sistem yang berfokus pada implementasi FPGA ringan algoritma kriptografi Enkripsi Algoritma TEA untuk beradaptasi dengan banyak kendala real time seperti memori, kehilangan data dan biaya rendah. Skema yang diusulkan menggunakan Linear Feedback Shift Register untuk menghasilkan kunci acak sehingga lebih aman untuk transfer informasi sensitif di banyak aplikasi real time [7].

Peneliti lain mengimplementasikan algoritma enkripsi yang digunakan untuk keamanan lebih komunikasi nirkabel, tetapi mengamankan data juga mengkonsumsi sumber daya. Faktor penting utama yang perlu dipertimbangkan ketika merancang sistem kriptografi adalah kinerja, kecepatan, ukuran, dan keamanan. Tiny Encryption Algorithm (TEA), dan eXtended TEA (XTEA) adalah contoh dari algoritma kriptografi. Tiny Encryption Algorithm (TEA) adalah algoritma kriptografi yang dirancang untuk meminimalkan pemakaian memori dan memaksimalkan kecepatan. Ini adalah jenis cipher feistel yang menggunakan operasi dari campuran (orthogonal) kelompok aljabar [8].

Penelitian selanjutnya menggunakan algoritma Base64 dengan mengubah struktur index-nya yang bertujuan untuk menghamburkan makna dari plaintext ketika ciphertext dicoba untuk dipecahkan oleh 
pemecah kode. Pemodelan data rrpemograman C\#. Dengan adanya cara pengamanan ini, pengembang aplikasi yang menggunakan bahasa pemrograman PHP dapat menyembunyikan skrip PHP supaya tidak mudah disalin, diubah sebagian/seluruhnya oleh orang yang tidak berhak dan dapat mengamankan kelemahan dari alur program aplikasi PHP [9], [10].

Oleh sebab itu penulis melakukan penerapan algoritma kriptografi tea dan base64 untuk mengamankan email data policy asuransi pada PT. Dekai Indonesia.

\section{Metode Penelitian}

\section{A. Analisa Kebutuhan}

Menganalisis masalah, kebutuhan, keperluan, dan penggunaan apa saja yang akan diperlukan untuk pengamanan dokumen di PT. Dekai Indonesia. Adapun teknik pengumpulan data yang digunakan yaitu sebagai berikut.

1) Perencanaan, mengidentifikasi masalah-masalah keamanan dokumen di PT. Dekai Indonesia.

2) Penelitian lapangan, yaitu melakukan observasi atau praktek lapangan secara langsung di perusahaan terkait guna mendapatkan data yang akurat dan dapat dipertanggung jawabkan keabsahannya. Adapun teknik pengumpulan data yang digunakan yaitu:

a) Studi lapangan, yaitu penelitian langsung di PT. Dekai Indonesia yang diteliti untuk mendapatkan data serta informasi yang diperlukan, seperti data penting perusahaan yang memiliki format file .pdf, .ppt, .doc, .xls, .xlsx dan .jpg.

b) Pengamatan, yaitu teknik pengumpulan data dengan mengamati langsung proses pembuatan file dan pengiriman file yang berisikan data-data penting perusahaan.

c) Studi dokumentasi, yaitu mempelajari dokumen - dokumen yang berkaitan dengan permasalahan yang dibahas.

d) Metode wawancara, merupakan proses tanya jawab langsung dan sistematis kepada orang yang mengetahui tentang permasalahan yang sedang diamati untuk menyakinkan hal - hal kegiatan observasi yang telah dilakukan.

e) Penelitian kepustakaan, yaitu penelitian yang dilakukan dengan cara mempelajari literature - literatur, buku - buku, jurnal dan artikel ilmiah yang berhubungan dengan serta cara kerja algoritma TEA .

\section{B. Desain Sistem}

Persiapan rancang bangun implementasi pada PT. Dekai Indonesia yang menggambarkan bagaimana suatu sistem dibentuk yang berupa penggambaran, Desain web adalah tahap yang harus dilakukan sebelum mulai membuat situs web. Konsep rancangan dalam mendesain halaman web adalah tampilan pada halaman browser yang akan diakses oleh pengguna.

\section{Ujicoba program}

Ujicoba mempresentasikan ketidak normalan yang terjadi pada pengembangan program dengan bahasa pemrograman PHP kepada semua jenis file yang digunakan PT. Dekai Indonesia, jenis file yang digunakan diantaranya $. p d f, . p p t, . d o c, . x l s, . x l s x$ dan.$j p g$. Selama definisi awal dan fase pembangunan, pengembangan berusaha untuk membangun program dari konsep yang abstrak sampai dengan implementasi yang memungkinkan.

\section{Implementasi}

Tahap dimana semua elemen dan aktivitas sistem disatukan dengan langkah - langkah, sebagai berikut.

1) Menyiapkan Fasilitas Fisik, fasilitas - fasilitas fisik yang disiapkan antara lain komputer dan peripheralnya, termasuk keamanan fisik untuk menjaga berlangsungnya peralatan dalam jangka waktu yang lama.

2) Menyiapkan pengguna, pemakai disiapkan dengan terlebih dahulu yaitu dengan memberikan pelatihan secara prosedural maupun tutorial mengenai program. Tujuannya adalah agar para pengguna mengerti dan mengusai cara kerja program. 
3) Melakukan Simulasi, kegiatan simulasi berupa pengujian program secara nyata yang melibatkan personil yang sesungguhnya.

\section{PEMbangunan PerangKat LunaK}

Perancangan sistem yang dibuat secara umum adalah pengiriman mail encrypt dan penerima mail decrypt menggunakan metode TEA berbasis web, adapun beberapa tahap dalam perancangan aplikasi adalah sebagai berikut.

\section{A. Proses}

Perancangan proses yang dimaksudkan adalah bagaimana sistem akan bekerja, proses-proses yang digunakan mulai dari user mengakses halaman web, lalu menulis pesan dan attach file untuk dienkripsi, kemudian diproses oleh aplikasi sehingga dapat mengeluarkan output berupa hasil encrypt pesan tersebut. Perancangan proses aplikasi untuk mengamankan data policy asuransi dapat dilihat pada Gambar 1.

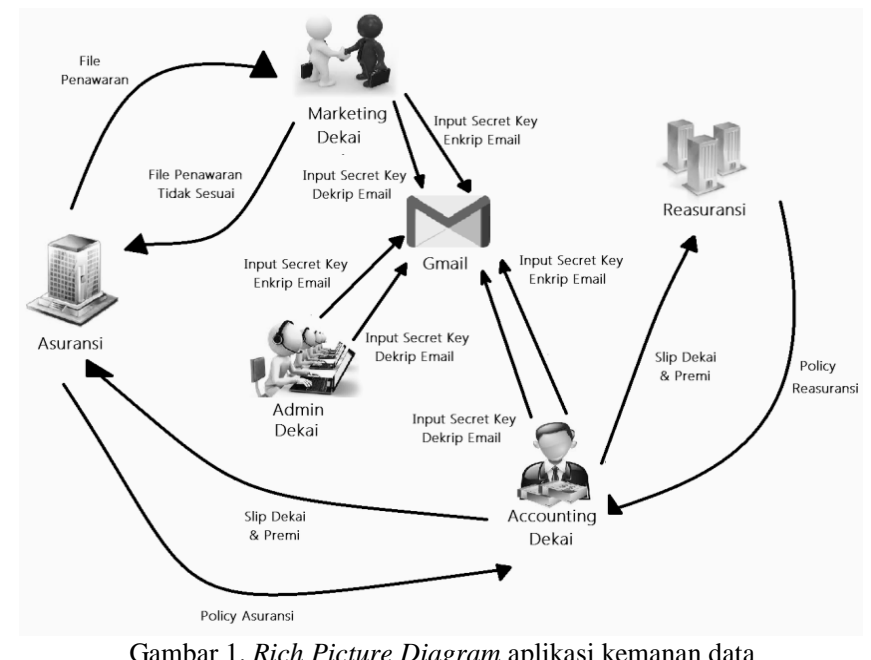

Gambar 1. Rich Picture Diagram aplikasi kemanan data

\section{B. Use Case Diagram dan Activity Diagram}

Tahap pertama dalam perancangan sistem adalah membuat Use Case Diagram. Use Case Diagram adalah rancangan yang digunakan untuk menggambarkan kebutuhan dan fungsionalitas dan sudut pandang user berdasarkan hasil analisa yang telah dilakukanm dapat dilihat pada Gambar 2.

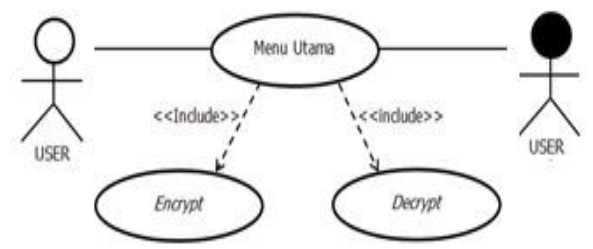

Gambar 2. Use Case Diagram aplikasi keamanan data

\section{Antar Muka Pemakai}

Perancangan antar muka mengandung penjelasan tentang desain dan implementasi sistem yang digunakan dalam sistem yang dibuat. Proses perancangan aplikasi mail encrypt dan decrypt menggunakan metode enkripsi Tea berbasis web secara umum dapat diuraikan sebagai berikut :

a) Masukan pesan, file dan key yang akan dikirim lalu disandikan ke dalam aplikasi yang sedang berjalan.

b) Proses pesan dan file asli dengan menggunakan encrypt metode Tea.

c) Dari proses encrypt tersebut maka akan menghasilkan kode-kode yang acak yang di dalamnya telah disisipi pesan rahasia.

d) Proses mail decrypt Proses atau tahap yang dilakukan untuk membaca pesan yang telah disandikan dengan melakukan decrypt pesan tersebut untuk membacanya kembali. 
Pada menu encryption mail akan langsung ditampilkan menu untuk melakukan input pesan dan upload file seperti yang terlihat pada Gambar 3 .

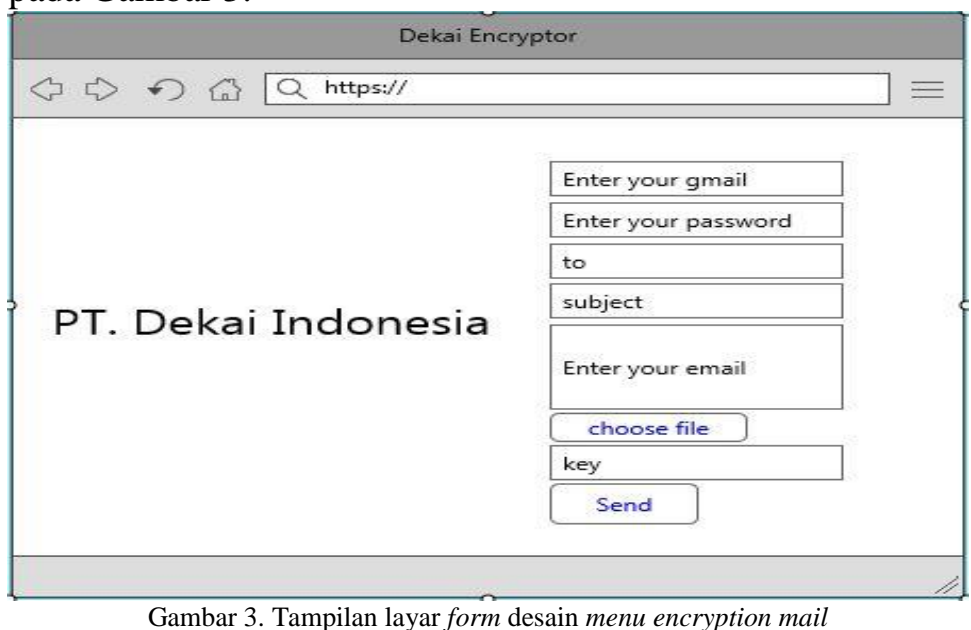

Pada tampilan halaman encrypt ini ada beberapa menu yang berfungsi sebagai berikut.

1) Home, untuk kembali ke menu utama (home).

2) Gmail ID, kolom yang berfungsi untuk memasukan user id Gmail.

3) Password, kolom yang berfungsi untuk memasukan password Gmail yang telah dimasukan sebelumnya.

4) To, kolom berfungsi untuk memasukkan alamat gmail yang dituju.

5) Subject, kolom yang berfungsi untuk memasukan subject email yang akan dikirim.

6) Choose file, tombol yang berfungsi untuk memiih file yang akan diunggah.

7) Secret Key, kolom yang berungsi untuk memasukan secret key.

8) Send, tombol send berfungsi untuk mengirimkan pesan sekaligus untuk proses enkripsi.

Pada saat user hendak mengirimkan pesan dengan enkripsi maka diperlukan untuk memasukan secret key yang terdiri dari 16 character dan case sensitif, diwajibkan bagi user untuk mengingat secret key yang dimasukan, karena nantinya secret key ini akan digunakan kembali saat penerima email hendak membuka email ini kembali.

\section{Algoritma encrypt TEA}

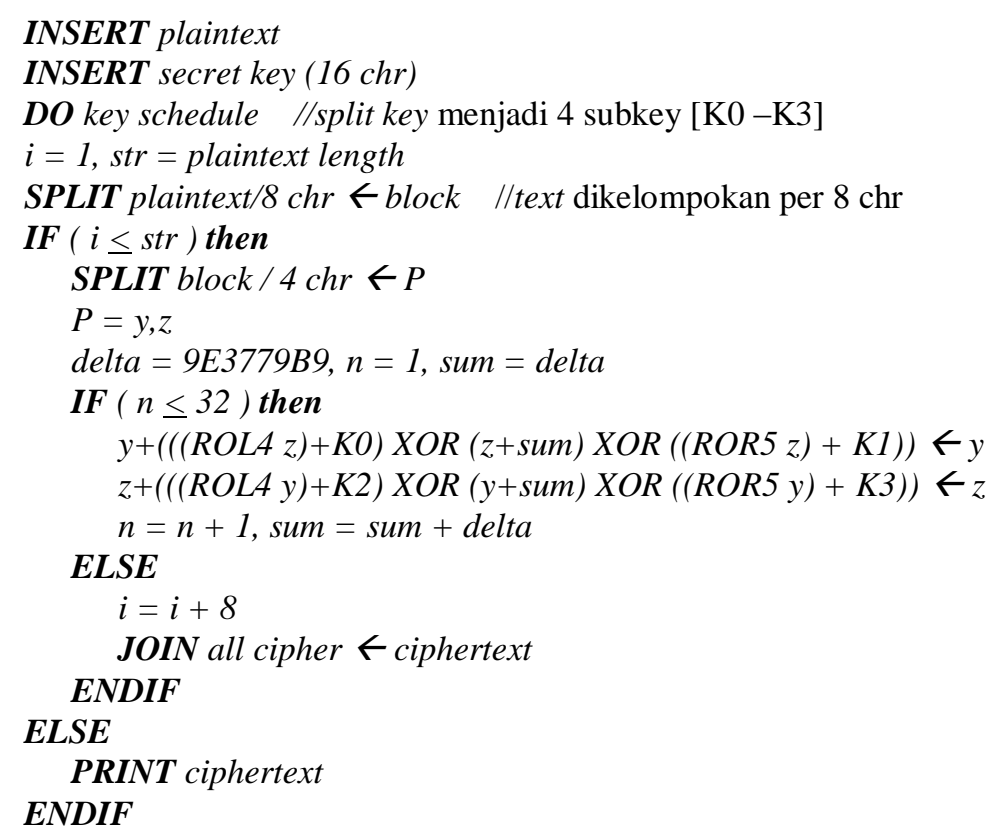




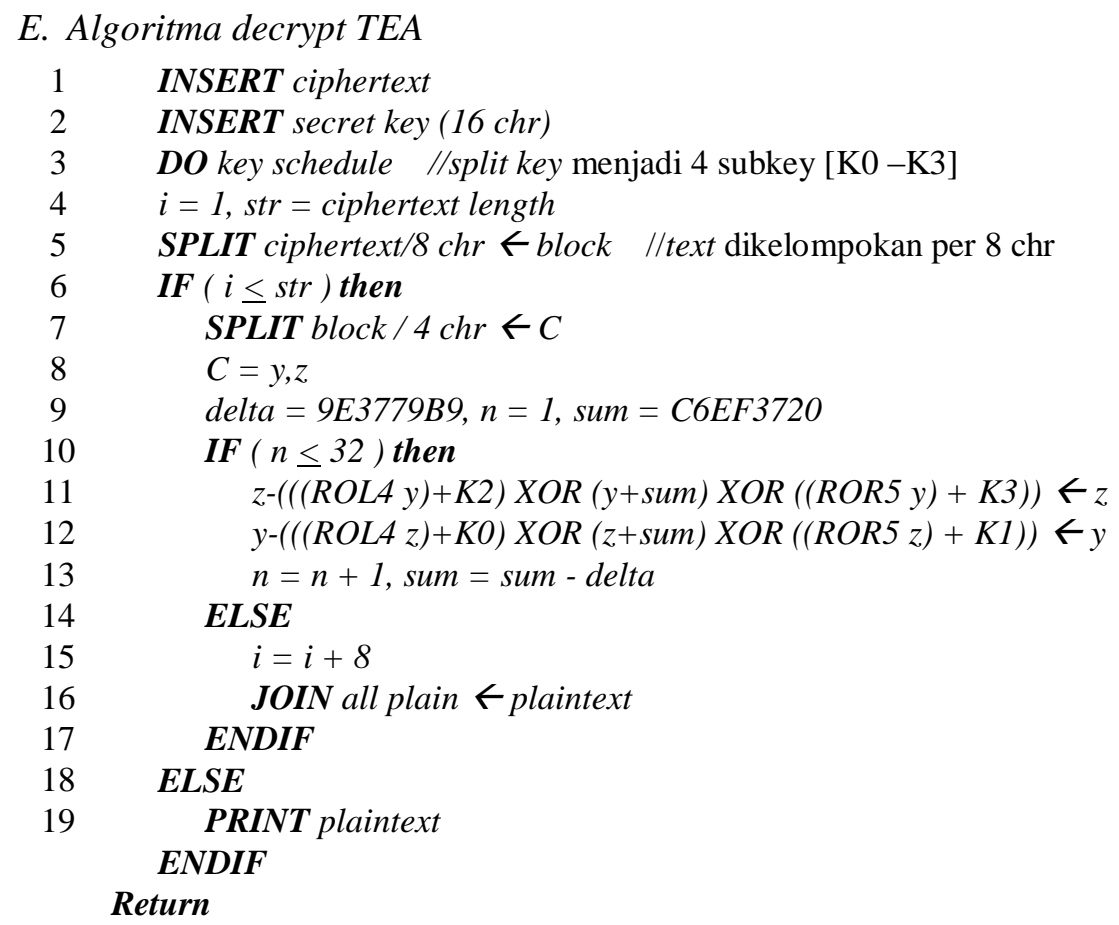

\section{F. Algoritma proses encrypt base64}

Algoritma proses encrypt base64 dari mulai input karakter ASCII, lalu penghitungan padding, lalu pemecahan menjadi per 6 bit sampai tahap konversi. Berikut adalah pseudo code proses encoding base64.

1 Input karakter ASCII(plaintext)

2 Hitung panjang byte(plaintext)

3 If panjang byte(plaintext) dapat dibagi 3 then

$4 \quad$ Hitung panjang binary(plaintext)

5 Else If penambahan padding 1 byte dapat dibagi 3 then

$6 \quad$ Hitung panjang binary(plaintext)

$7 \quad$ Else Tambakan 1 byte pada plaintext

8 Hitung panjang binary(plaintext)

$9 \quad$ Endif

10 Endif

11 Buat pengelompokan masing-masing 6 bit

12 Tampilkan encrypt

\section{G. Algoritma proses decrypt base64}

1 input string ciphertext

2 input key

3 hitung panjang byte(ciphertext)

$4 \quad$ hitung panjang binary(ciphertext)

$5 \quad$ hasil konversi $\leftarrow$ kelompokkan per 8 bit

$6 \quad$ Hilangkan hasil konversi

7 Tampilkan decrypt

\section{PENGUJIAN SisteM}

Proses pengujian pada aplikasi pada sepuluh file dengan ukuran $<5 \mathrm{MB}$, maka didapatkan hasil seperti pada Tabel 2. 


\begin{tabular}{|c|c|c|c|c|c|c|}
\hline \multirow[b]{2}{*}{ No } & \multirow[b]{2}{*}{ Nama File } & \multicolumn{2}{|c|}{ Sebelum Encrypt } & \multirow{2}{*}{$\begin{array}{c}\text { Ukuran file } \\
\text { encrypt } \\
\text { (bytes) }\end{array}$} & \multirow{2}{*}{$\begin{array}{l}\text { Lama Proses } \\
\text { Encrypt }(\mathrm{ms})\end{array}$} & \multirow{2}{*}{$\begin{array}{c}\text { Tambahan } \\
\text { Ukuran File } \\
(\%)\end{array}$} \\
\hline & & $\begin{array}{l}\text { Format } \\
\text { File }\end{array}$ & $\begin{array}{l}\text { Ukuran File } \\
\text { (bytes) }\end{array}$ & & & \\
\hline 1 & $\begin{array}{l}\text { Attachment of PT. DAN LIRIS - } 2017 \text { - } \\
2018 \text { - insurer }\end{array}$ & pdf & 312066 & 416158 & 0.858 & 32.4207 \\
\hline 2 & PT. Sumatera Tobbaco 17.11.2014 & bmp & 239125 & 318898 & 0.669 & 33.3603 \\
\hline 3 & Dekai & jpg & 21617 & 28894 & 0.064 & 33.6633 \\
\hline 4 & PT. LAJU PERDANA PATI & tif & 239331 & 319174 & 0.666 & 33.3609 \\
\hline 5 & Dekai Insurance & ppt & 289295 & 385778 & 0.810 & 33.3511 \\
\hline 6 & $\begin{array}{l}\text { Final Slip - PAR - PT. DAN LIRIS and or } \\
\text { PT. AMBASSADOR GARMINDO and or } \\
\text { PT. EFRATA RETAILINDO and or PT. } \\
\text { MULTIYASA ABADI SENTOSA - } 2017 \text { - } \\
2018 \text { - insurer }\end{array}$ & doc & 45583 & 60830 & 0.13 & 33.4489 \\
\hline 7 & Naruto chapter 3 & $\mathrm{mp} 4$ & 1561427 & 2081970 & 4,633 & 33.3376 \\
\hline 8 & PT. UNITED CAN COMPANY LIMITED & pdf & 1607778 & 2143774 & 4.505 & 33.3377 \\
\hline 9 & $\begin{array}{l}\text { REVISI_HARGA PERTANGGUNGAN PT } \\
\text { KK_INDONESIA }\end{array}$ & pdf & 2142906 & 2857266 & 5.985 & 33.336 \\
\hline 10 & SUN̄GAI BUDI GROUP & pdf & 4322552 & 5763462 & 12.351 & 33.3347 \\
\hline \multicolumn{6}{|c|}{$\begin{array}{l}\text { Rata-rata penambahan ukuran file setelah dilakukan encrypt } \\
\text { dan rata-rata kecepatan proses encrypt per byte }=\end{array}$} & 33.29512 \\
\hline
\end{tabular}

Berdasarkan hasil percobaan proses encrypt pada sepuluh macam file tersebut, didapatkan kesimpulan di bawah ini.

1) Ukuran file setelah melalui proses encrypt akan berubah menjadi lebih besar dengan rata-rata ukuran file yang telah melalui proses encrypt bertambah sekitar 33,29512 persen dari ukuran asli file sebelum melalui proses encrypt.

2) Waktu yang dibutuhkan untuk melakukan proses encrypt dengan ukuran file kurang dari $5 \mathrm{MB}$ relatif cepat $(<15$ second $)$.

Setelah percobaan proses encrypt, dilakukan percobaan proses decrypt pada sepuluh file yang telah terencrypt pada percobaan sebelumnya, dan didapat hasil seperti pada tabel 3 ,

TABEL 3

TABEL PENGUJIAN DECRYPT FILE $<5 \mathrm{MB}$

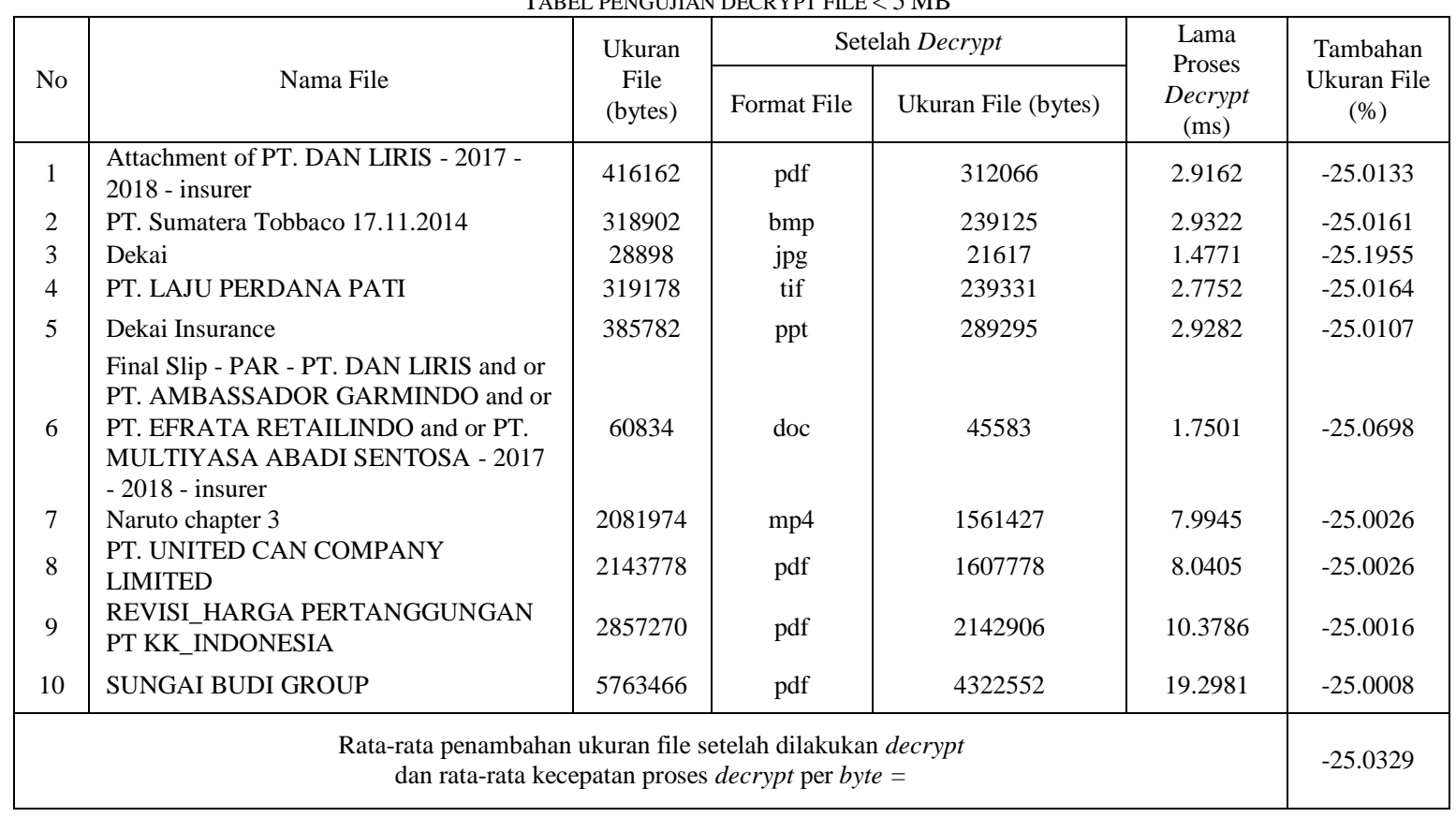

Berdasarkan hasil percobaan proses decrypt pada sepuluh file didapatkan kesimpulan yaitu sebagai berikut.

1) Ukuran file setelah melalui proses decrypt akan berubah menjadi ukuran awal file sebelum encrypt. Rata-rata perubahan ukuran file akan berkurang sebesar 25.0329 persen, sama dengan rata-rata pada proses encrypt. 
2) Waktu yang dibutuhkan untuk melakukan proses decrypt dengan ukuran file kurang dari $5 \mathrm{MB}$ relatif cepat $(<20$ second $)$.

\section{KESIMPULAN}

Berdasarkan hasil penelitian dan pembahasan serta uji coba sistem dapat disimpulkan, sebagai berikut :

a. Pegamanan email dapat diamankan dengan algortima kriptografi TEA.

b. Data tidak dapat dibuka oleh pihak yang tidak berhak yang tidak memiliki kunci.

c. Program sistem keamanan dengan sistem kriptografi algoritma TEA telah diuji coba, sehingga program dinyatakan sudah sesuai.

d. Ukuran file setelah melalui proses encrypt akan bertambah besar dibandingkan dengan ukuran file awal sebelum dilakukan proses encrypt.

e. Ukuran file untuk dilampirkan yang paling optimal untuk aplikasi ini adalah 5242880 bytes (5 MB) . Jika ukuran diatas 5242880 bytes (5 MB) proses akan sedikit lebih lama dan untuk ukuran file di atas 10485760 bytes (10 MB ) tidak bisa diproses.

f. Rata-rata ukuran file yang telah melalui proses encrypt bertambah sekitar 33,29512 persen dari ukuran asli file sebelum melalui proses encrypt.

g. Rata-rata perubahan ukuran file yang telah melalui proses decrypt akan berkurang sebesar 25.0231 persen.

h. Proses pengiriman email encrypt tergantung dengan koneksi internet yang digunakan, sehingga proses pengiriman email encrypt bisa cepat atau lama

\section{DAFTAR PUSTAKA}

[1] N. W. Group, "RFC 5321 - Simple Mail Transfer Protocol.” .

[2] J. Leyden, "US court test for rights not to hand over crypto keys," Regist., 2011.

[3] W. Stallings, Network and Internetwork Security. Prentice Hall Inc, 1995.

[4] A. Kurniawan, Konsep dan Implementasi Cryptography dengan .NET. Dian Rakyat.

[5] I. Setiawan, "Aplikasi Kriptografi Dengan Algoritma Tiny Encryption Algorithm Menggunakan Microsoft Visual Basic," Universitas Mercu Buana, 2017.

[6] D. U. Daihani, Sistem Pendukung Keputusan. Jakarta: Elex Media Komputindo, 2001.

[7] G. Qian, S. Sural, Y. Gu, and S. Pramanik, "Similarity between Euclidean and cosine angle distance for nearest neighbor queries," in Proceedings of the 2004 ACM symposium on Applied computing - SAC '04, 2004, p. 1232.

[8] M. Shoeb and V. K. Gupta, “A Crypt Analysis Of The Tiny Encryption Algorithm In Key Generation,” Int. J. Comput. Technol., vol. 1, no. 38, 2013.

[9] A. T. Sholeh, E. Gunadhi, and A. Supriatna, "Mengamankan Skrip Pada Bahasa Pemograman PHP Dengan Menggunakan Kriptografi Base64,” J. Algoritm. Sekol. Tinggi Teknol. Garut, vol. 10, no. 1, 2013.

[10] R. Khoirianti, N. Hidayah, and V. Widyaningsih, "Implementasi Algoritma Tea Untuk Enkripsi Dan Dekripsi Menggunakan Bahasa Pemrograman Visual Basic,” Academia, 2014. 